\title{
EFFECT OF DOISYNOLIC ACID ON EXPERIMENTAL ATHEROMA IN THE COCKEREL
}

BY

\author{
R. S. F. CAMPBELL, T. D. V. LAWRIE, J. C. MACLAURIN, AND R. PIRRIE
}

From the Department of Veterinary Pathology, University of Glasgow, and the Department of Cardiology, Glasgow Royal Infirmary

Received October 14, 1958

The striking difference in the incidence of atherosclerosis in men and women has drawn attention to the possible protective value of cstrogens (Katz and Stamler, 1953). A good degree of protection against coronary atheroma in cholesterol-fed chickens can be given by endogenous œestrogen in physiological proportions (Pick et al., 1953) as well as by administered œstradiol benzoate (Pick et al., $1952 a$ and $b$ ). In contrast, œstradiol benzoate is ineffectual against aortic lesions. Mixed conjugated œstrogens (premarin) and parenteral diethyl-stilbœstrol resemble œstradiol in their ability to inhibit coronary lesions (Stamler et al., 1953).

The feminizing effect of œstrogens is an obvious deterrent to their use in the treatment of human atherosclerosis and attempts have been made to obviate this difficulty by using structurally-related substances of low potency. Stamler et al. reported a lack of success. Recently, Cook et al. (1958) described lipid-depressing effects with a newer steroid of weak astrogenicity. The work described here concerns methoxy bisdehydro-doisynolic acid-7-benzoate (MDDA).

\section{Materials AND Methods}

The experiment was similar to that devised by Pick et al. $(1952 \mathrm{~b})$. Seventy-two Golden Legbar $\times$ Light Sussex cockerels, a breed previously tested for susceptibility to experimental atheroma, were obtained at the age of eight weeks from the West of Scotland Agricultural College Poultry School. After placing in individual cages, the birds were fed ad libitum on the particular diet for eight weeks, with the exception of one group killed at five weeks to prove the establishment of lesions prior to treatment. The daily food intake was estimated once a week from the fifth week onwards (Table I) and the birds were weighed on the first, fifth, and eighth weeks (Fig. 1).

The normal and treated control groups (1 and 2) received commercial chick mash, others being given chick mash into which was incorporated 2 per cent cholesterol and 5 per cent cottonseed oil by means of a food mixer. The experiment included the following groups of twelve birds.

(1) Normal diet only.

(2) Normal diet with $5 \mathrm{mg}$. MDDA intramuscularly daily, during 6th to 8th weeks inclusive.

(3) Cholesterol diet only.

(4) Cholesterol diet with $1 \mathrm{mg}$. MDDA intramuscularly daily during 6th to 8th weeks inclusive.

(5) Cholesterol diet with $5 \mathrm{mg}$. MDDA intramuscularly daily, during 6th to 8th weeks inclusive.

(6) Cholesterol diet: killed after five weeks.

At autopsy the heart, brachiocephalic arteries, aorta, and first part of the iliac arteries were examined microscopically for atheroma, and any lesions classified in slight, moderate, and severe grades. Slight implies focal lesions up to about $2 \mathrm{~mm}$. in diameter, white or cream-coloured, accompanied by minimal thickening of the intima. Moderate implies plaques up to about $5 \mathrm{~mm}$. in diameter, cream to ivory-yellow in colour, with distinct intimal thickening and linear ("treetrunk") ridging. Severe implies larger plaques of cream to yellow colour merged into diffuse atheroma, with distinct thickening and ridging or distortion of the wall. 
After fixation in 10 per cent formol sailine, three transverse slices were taken from the broadest part of the heart. One frozen section was prepared from each slice, stained by Sudan IV and hæmalum, and a microscopical count of atheromatous coronary arteries carried out. Criteria for the presence of atheroma were intimal thickening or plaque formation. Sudanophilia of intima or media without structural change was regarded as a negative finding.

TABLE I

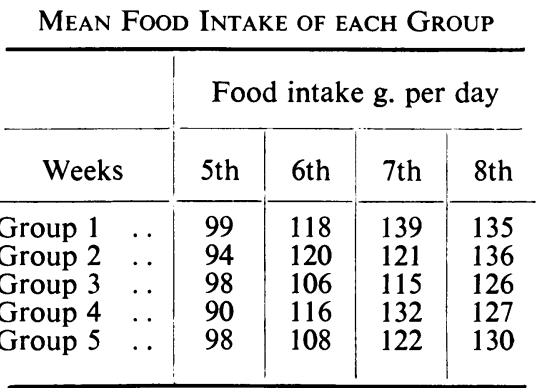

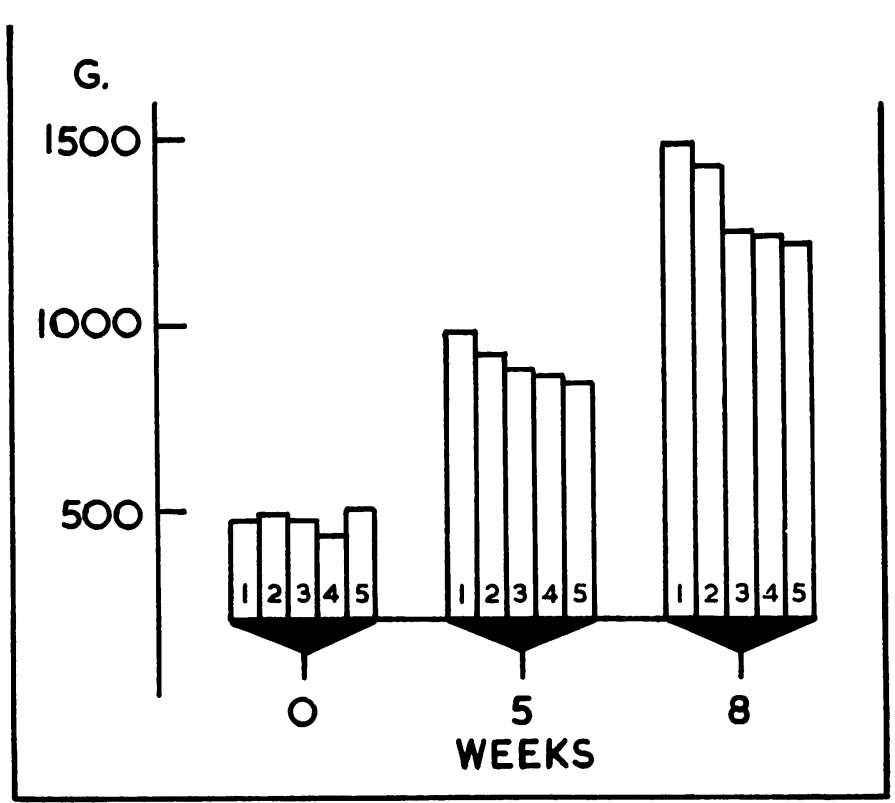

Fig. 1.-Mean body-weight of each group, at the start, after five weeks, and after eight weeks.

\section{RESULTS}

Sexual Inhibition. Birds receiving MDDA showed a varying degree of inhibition of sexual development, as judged by gross examination. It was seen that in those on a regime of $5 \mathrm{mg}$. the testes were small and the comb and wattles undersized as compared with the normal group. Of the birds receiving $1 \mathrm{mg}$. MDDA daily, inhibition occurred in eight; the remaining four showed testes, comb, and wattles of normal size.

Atheroma. (a) Aorta. The incidence of aortic lesions is presented in Table II. The cholesterolinduced lesions were more severe in the thoracic than in the abdominal aorta as noted by Dauber and Katz (1942). Indeed the abdominal lesions were absent from a majority of birds. The incidence of aortic lesions, however, was not affected by MDDA but was similar in the three groups receiving cholesterol. 
TABLE II

The Incidence of Aortic Atheroma

\begin{tabular}{|c|c|c|c|c|c|c|}
\hline \multirow{2}{*}{$\begin{array}{c}\text { Vessel } \\
\text { examined }\end{array}$} & \multirow{2}{*}{$\begin{array}{l}\text { Degree of } \\
\text { atheroma }\end{array}$} & \multicolumn{5}{|c|}{ Group } \\
\hline & & 1 & 2 & 3 & 4 & 5 \\
\hline \multirow{4}{*}{$\begin{array}{l}\text { Thoracic } \\
\text { aorta }\end{array}$} & Severe & 0 & 0 & 6 & 3 & 6 \\
\hline & Moderate & 0 & 0 & 6 & 7 & 6 \\
\hline & Slight & 0 & 0 & 0 & 2 & 0 \\
\hline & Absent & 12 & 12 & 0 & 0 & 0 \\
\hline \multirow{4}{*}{$\begin{array}{l}\text { Abdominal } \\
\text { aorta }\end{array}$} & Severe & 0 & 0 & 0 & 0 & 0 \\
\hline & Moderate & 0 & 0 & 2 & 2 & 1 \\
\hline & Slight & 1 & 0 & 2 & 3 & 2 \\
\hline & Absent & 11 & 12 & 8 & 7 & 9 \\
\hline
\end{tabular}

(b) Coronary arteries. Analysis of variance shows no significant difference in the incidence of atheroma in the birds fed with cholesterol. The results of the arterial counts are shown in Table III.

TABLE III

Percentage Incidence of Coronary Artery Lesions

\begin{tabular}{cc|c|r}
\hline & & Mean & \multicolumn{1}{|c}{ Range } \\
\cline { 1 - 2 } Group 3 & $\ldots$ & $34 \cdot 7$ & $8 \cdot 3-48 \cdot 9$ \\
Group 4 & $\ldots$ & $22 \cdot 8$ & $4 \cdot 0-36 \cdot 2$ \\
Group 5 &. & $34 \cdot 2$ & $18 \cdot 0-52 \cdot 7$ \\
\hline
\end{tabular}

\section{Discussion}

It appears that MDDA in daily doses of 1 or $5 \mathrm{mg}$. for three weeks has no effect on the incidence of aortic or coronary atheroma in chickens produced by a 2 per cent cholesterol diet over an eightweek period. Further, there was clear evidence that the drug, especially in the higher dosage, exerted considerable œstrogenic activity.

Pick et al. $(1952 \mathrm{~b})$ demonstrated that in the cockerel œstradiol benzoate caused regression of established coronary lesions when given over the last five weeks of a thirteen-week period of cholesterol feeding. If this effect of œstradiol benzoate is a parallel function of its œstrogenicity, MDDA might have been expected to produce a similar trend, in view of the œstrogenic activity as judged by sexual inhibition in the present experiment. Its failure to do so suggests that astrogenicity is not necessarily a measure of the effect against atheroma. A similar tentative conclusion on lipid effects and œstrogenic properties was reached in respect of the steroid tested by Cook et al. (1958).

\section{SUMMARY}

The effects of methoxy-bisdehydro-doisynolic acid-7-benzoate on atheroma induced by cholesterol in cockerels is described. When given in daily doses of $1 \mathrm{mg}$. and $5 \mathrm{mg}$. over the latter three weeks of an eight-week feeding experiment it had no significant effect on the incidence of aortic or coronary artery atheroma. The significance of these findings is briefly discussed.

This research programme has been supported by a grant from the Scottish Hospital Endowments Research Trust.

We are indebted to Dr. J. H. Wright and Professor J. W. Emslie for their guidance and helpful criticism, to Dr. Hewett of Organon Laboratories Ltd. for his kindness in supplying the drug, and to Dr. R. A. Robb for his aid with the statisticai analysis of results. 
REFERENCES

Cook, D. L., Edgnew, R. A., and Saunders, F. J. (1958). Endocrinology, 6, 798.

Dauber, D. V., and Katz, L. N. (1942). Arch. Path., 34, 937.

Katz, L. N., and Stamler, J. (1953). Experimental Atherosclerosis. Thomas, Springfield, Illinois.

Pick, R., Stamler, J., Rodbard, S., and Katz, L. N. (1952a). Circulation, 6, 276.

$-,-,-1,(1952 b)$. Circulation, 6, 858 .

,-- and Katz, L. N. (1953). Circulation, 8, 436.

Stamler, J., Pick, R., and Katz, L. N. (1953). Circulation, 8, 436. 